\title{
Prácticas transformistas en el documental latinoamericano reciente: usos de la voz y flujos musicales
}

\author{
Agostina Invernizzi \\ Universidad de Buenos Aires - CONICET \\ agostina.invernizzi@gmail.com
}

\author{
Ezequiel Lozano \\ Universidad de Buenos Aires - CONICET \\ lozanoezequiel@gmail.com \\ Artículo bajo licencia Creative Commons \\ Atribución 4.0 Internacional (CC BY 4.0) \\ ENVIADO: $2019-10-20$ \\ ACEPTADO: 2020-09-02
}

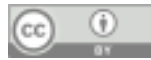

\section{RESUMEN}

El presente trabajo pretende ser un aporte al trazado de una cartografía torcida, a la construcción de un mapa de la geografía audiovisual sexodisidente en el cine documental de Latinoamérica, luego de décadas de una artillería audiovisual altamente transfóbica. En el cortometraje documental La Otra (1989), de Lucrecia Martel, se puede visibilizar un momento central del trayecto hacia una visibilidad trans en nuestra cinematografía. En ese trabajo estudiantil de la directora observamos algo inusual para el cine documental local y para los estudios teatrales latinoamericanos: el foco en las prácticas transformistas.

Nuestro primer esbozo de este mapa se extiende temporalmente desde 1989 hasta 2017 y establece un recorrido por Argentina, México, Venezuela, Cuba y Perú. Este corpus inicial lo conforman, además del trabajo de Martel, los siguientes cortometrajes: Es mi vida (el arte de la transformación) (Espinoza, 1995); Perra (Navarro, Plaza y González, 2011); El Arte de La Transformación (Uzcateguí y Castillo, 2016) y Nebulah (Montoro, 2017).

Reivindicando un posicionamiento específico dentro del campo del cine documental, y construyendo un archivo desviado del canon, proponemos aquí una mirada que reflexione sobre los usos de la voz y los flujos musicales en las prácticas drag presentadas en los films, las cuales desde hace décadas batallan contra la transfobia aún vigente en las sociedades occidentales e incluso visible en el discurso esgrimido por sus propixs artífices.

Palabras Clave

Transformismo, género, cine documental, cortometraje, performance.

\section{RESUMO}

O presente trabalho tem como objetivo contribuir para o traçado de uma cartografia torcida, para a construção de um mapa da geografia audiovisual dissidente de sexo no cinema documental da América Latina, após décadas de uma artilharia audiovisual altamente transfóbica. No curta-metragem documentário La Otra (1989), de Lucrecia Martel, um momento central da jornada pode ser tornado visível para a visibilidade trans em nossa cinematografia. Nesse trabalho estudantil da diretora, observamos algo incomum no cinema documental local e nos estudos de teatro latinoamericanos: o foco em práticas drag.

Nosso primeiro esboço deste mapa se estende temporariamente de 1989 a 2017 e estabelece um tour pela Argentina, México, Venezuela, Cuba e Peru. Esse corpus inicial é composto, além do trabalho de Martel, pelos seguintes curtas-metragens: Es mi vida (el arte de la transformación) (Espinoza, 1995); Perra (Navarro, Plaza y González, 2011); El Arte de La Transformación (Uzcateguí y Castillo, 2016) e Nebulah (Montoro, 2017).

Reivindicando um posicionamento específico no campo do cinema documental e construindo um arquivo desviado do cânone, propomos aqui um olhar que reflete sobre os usos dos fluxos de voz e musical nas práticas drag apresentadas nos filmes, que vêm lutando há décadas contra a transfobia ainda em vigor nas sociedades ocidentais e até visível no discurso exercido por seus próprixs arquitetxs.

\section{PALABRAS CLAVE}

Drag, gênero, cinema documental, curta-metragem, performance.

\section{ABSTRACT}

This article aims to be a contribution to the layout of a crooked cartography, to the construction of a map of the sexual dissident audiovisual geography in Latin America's documentary filmmaking, after many decades of highly transphobic audiovisual imagery. In the documentary short film La otra (Lucrecia Martel 1989), we find a fundamental moment of the journey towards trans* visibility in Argentinian cinematography. In Martel's student work, we observe something unusual for local documentary film and for Latin-American theater studies: the focus on drag performances.

Our first outline of this map extends from 1989 to 2017 and establishes a trail from Argentina, Mexico, Venezuela, Cuba, and Peru. This initial corpus consists of, in addition to Martel's work, by the following short films: Es mi vida (el arte de la transformación) (Espinoza, 1995); Perra (Navarro, Plaza and González, 2011); El Arte de La Transformación (Uzcateguí and Castillo, 2016), and Nebulah (Montoro, 2017).

By claiming a specific positioning within the field of documentary cinema and building an archive that deviates from the canon, we put forward a perspective that reflects on the uses of the voice and musical flows in the drag performances presented in the films, performances that for decades have battled against transphobia, which is still active in Western societies and also present in some of the films' protagonists' own discourse.

KEYWORDS

Drag, gender, film, documentary, short film, performance. 


\section{INTRODUCCIÓN}

El presente trabajo pretende ser un aporte al trazado de una cartografía torcida, a la construcción de un mapa de la geografía audiovisual sexo-disidente en el cine documental de latinoamérica, luego de décadas de una artillería audiovisual altamente transfóbica. En el cortometraje documental La Otra (1989), de Lucrecia Martel, se puede visibilizar un momento central del trayecto hacia una visibilidad trans $^{\star 1}$ en la producción audiovisual rioplatense. En ese trabajo estudiantil de la directora observamos algo inusual para el cine documental local y para los estudios teatrales latinoamericanos: el foco en las prácticas transformistas. Y, si bien el transformismo como tal tiene una larga presencia en el teatro de nuestra América (cf. Campuzano, 2007; Figari, 2009; Lozano, 2015), no siempre se lo mostró (ni fue leído) en su carácter más disruptivo como cuestionador del binarismo de género hegemónico; por ello creemos que su actual emergencia en el campo del cortometraje documental de los países de la región resulta alentadora para pensar la disidencia sexo-genérica en el arte latinoamericano.

Nuestro primer esbozo de este mapa se extiende temporalmente desde 1989 hasta 2017 y establece un recorrido por Argentina, México, Venezuela, Cuba y Perú. Este corpus inicial lo conforman los cortometrajes: La Otra (Martel, 1989); Es mi vida (el arte de la transformación) (Espinoza, 1995); Perra (Navarro, Plaza y González, 2011); El Arte de La Transformación (Uzcateguí y Castillo, 2016) y Nebulah (Montoro, 2017).

En la mayor parte de estos cortos, se puede observar la referencia al concepto de transformismo así como visualizar, en las producciones más cercanas en el tiempo, la mención del concepto importado, drag queen. Por ello, nos interesa, particularmente, de este corpus, su posibilidad de ser leído como deriva de discursos sociales latinoamericanos sobre una misma práctica a lo largo de los años: resulta significativo el pasaje desde una autopercepción en término de transformismo (ej.: en el cortometraje La Otra de 1989) hacia una mirada de sí atravesada por la internacionalización del término drag (en el corto Nebulah de 2017). Si bien Ixs entrevistadxs refieren a la misma práctica, la cual entienden de manera artística, el cambio en el modo de nombrarla también da cuenta de otro tipo de transformaciones en los discursos de quienes las llevan adelante.

Desde Perú, Giuseppe Campuzano (1969 - 2013) definió el término drag queen², especificando que "lo drag puede corresponder a una profesión, pero no a un estilo de vida, como sí el travestismo. Otra de sus diferencias se halla en sus fines estéticos. Así, mientras el travestismo «mimetiza», lo drag "dramatiza» lo femenino" (2007:90). Cierra su definición subrayando una situación propia de Perú (aunque ésta se repite en varios países), donde el término drag "es esgrimido para tomar distancia de lo travesti ante sus connotaciones peyorativas" (90). Como veremos, esta separación enunciada por lxs artistas entre una práctica y una lucha identitaria se hace explícita en el recorrido histórico de los discursos, enunciados en los diferentes cortos que aquí analizaremos. Por ello, creemos que el recorte propuesto en

Jack Halberstam (2018) sugiere que el asterisco podría interpretarse como un signo de interrogación o como uno que enfatiza el proceso de transición, en lugar de una forma final. Se trata de una conceptualización que alcanza diferentes identidades de género, en todo su espectro. De acuerdo con su investigación, el término trans* resiste la polarización y la oposición binaria, abriendo, así, infinitas posibilidades.

Definió el término drag queen del siguiente modo: "El término resulta del «polari» (argot usado por homosexuales de la clase obrera de Londres durante las décadas de 1950 y 1960), donde drag proviene de la sigla equivalente a «enters dressed as a girl» (entra en escena vestido como chica), que Shakespeare anotaba en los márgenes de sus libretos en tiempos del teatro isabelino, cuando los papeles femeninos eran representados por hombres; queen corresponde a homosexual afeminado. Lo drag puede corresponder a una profesión, pero no a un estilo de vida, como sí el travestismo. Otra de sus diferencias se halla en sus fines estéticos. Así, mientras el travestismo «mimetiza», lo drag «dramatiza» lo femenino. El travesti se desarrolla a un nivel cotidiano, mientras el drag queen lo «performa», y muchas veces lo rebasa, provisto ya de resonancias míticas - esto también es válido para el transformista, aunque los límites no son precisos. Desde su decisiva participación en los disturbios de Stonewall, los drag queens, que en 1969 combatieron los abusos de la policía de Nueva York - tales como el arresto de hombres travestidos-, conllevan una dimensión política. No obstante, en Lima y en otras ciudades del Perú, ésta faceta es dejada de lado, y el término es esgrimido para tomar distancia de lo travesti ante sus connotaciones peyorativas" (Campuzano, 2007:90). 
este trabajo requiere una escucha que dé cuenta de éstos, incluso con sus contradicciones y sus posicionamientos, diferenciados al desarrollo paralelo que ha tenido el pensamiento travesti, junto a sus avances teóricos y legislativos.

Porque, cierto es también, las luchas travestis y trans* en América Latina han logrado avances gigantescos durante los años que recorre nuestro corpus. En Argentina, por ejemplo, la producción de pensamiento travesti es de una solidez categórica (por citar sólo dos ejemplos: Berkins, 2007; Wayar, 2018). Asimismo, en la Facultad de Filosofía y Letras de la Universidad de Buenos Aires se creó, recientemente, un espacio central como la Cátedra Libre de Estudios Trans*, llevada adelante por dos referentes del activismo actual de la talla de Mauro Cabral Grinspan y Blas Radi Es notorio que el contexto latinoamericano en general, y el argentino en particular, ha cambiado desde el año 1989 cuando se produjo el cortometraje de Martel que da inicio temporal al corpus. Y es disímil la realidad sociocultural y política de cada país de la región. Aun así, entendemos que una mirada de conjunto sobre estos materiales puede ser un aporte sobre un objeto de estudio poco visitado hasta el presente en esta región.

Reivindicando un sitio específico dentro del campo del cine documental, y construyendo un archivo desviado del canon, proponemos aquí una mirada que reflexione sobre los usos de la voz y los flujos musicales en las prácticas drag presentadas en los films, las cuales desde hace décadas batallan contra la transfobia, aún vigente en las sociedades occidentales (inclusive reconocible, por momentos, en el propio discurso esgrimido por sus artífices). Sería imposible abarcar en un solo artículo la totalidad de materiales documentales sobre el tema en un lapso temporal tan extenso, por ello creemos que recortar nuestra mirada a la producción de cortometrajes es una manera de comenzar con una labor que podría ser ampliada y continuada en trabajos posteriores. A su vez, consideramos que el recorte temporal que dibuja el corpus es apropiado para percibir las continuidades y los cambios producidos en los discursos sobre una misma práctica. Asimismo, el mapa geográfico trazado extiende espacialmente esta perspectiva.

A primera vista resulta singular, en los films que conforman este corpus, la alternancia de entrevistas personales a lxs performers con fragmentos de su arte en escena. O sea, la presencia en los shows, rebosante de brillos, pelucas y purpurina, contrasta con la voz de un cuerpo autopercibido masculino que relata las zonas más amargas del tránsito vital hasta llegar

En materia legislativa, destacamos la Ley de Identidad de Género promulgada en el año 2012; y la Ley de Cupo Laboral Trans, impulsada por Diana Sacayán, sancionada en la provincia de Buenos Aires en el año 2015. Para más información véase: Torres Costa, Majo (2015). "Desde la exclusión al reconocimiento. Ciudadanías trans en Buenos Aires de los años 90 a la actualidad" en Memorias, identidades y experiencias trans: (In)visibilidades entre Argentina y España, Peralta, Jorge Luis y Mérida Jiménez, Rafael M. (eds.), Buenos Aires: Editorial Biblos. al escenario, espacio que se valora como único para poder alcanzar una libertad expresiva y una felicidad personal.

Este contraste que se reitera como leimotiv en todos los documentales se asienta asimismo en un tópico que aparece en el discurso de estxs artistas: el desdoblamiento entre una performatividad de género que adscribe a la masculinidad asignada al nacer y otra, femenina, que se desarrolla como un arte. Esta identidad mutable pareciera presentarse como una característica que estas personas valoran positivamente, lo cual también les lleva a diferenciarse de la identidad travesti (y en este punto es donde emerge, en algunos casos, la transfobia del discurso que erigen).

Esta idea de desdoblamiento también se observa en el nivel de puesta en escena por medio del recurso de espejos y pantallas que multiplican la imagen, presente en todos los films. Muchas entrevistas suceden dentro del camarín mientras se opera la transformación performática hacia un determinado modelo de feminidad pretendido. Es en el corto venezolano El Arte de La Transformación (Isaac Uzcateguí y Pavlo Castillo, 2016) ${ }^{4}$ donde se plantea de manera más radical esta figuración que propone llegar a la "esencia de la mujer" mediante el transformismo como práctica artística. Se diferencia del resto del corpus porque las prácticas transformistas que recorta se encuadran dentro de un concurso de belleza "Miss Venezuela Gay Centro", poniendo en foco la situación de competencia donde todas ganan algún título, como, por ejemplo: "Miss figura" o "Piel más bella". A su vez, el título mismo del certamen engloba la práctica dentro de "lo gay", optando claramente más por su costado de nicho de mercado antes que como reivindicación política de una identidad.

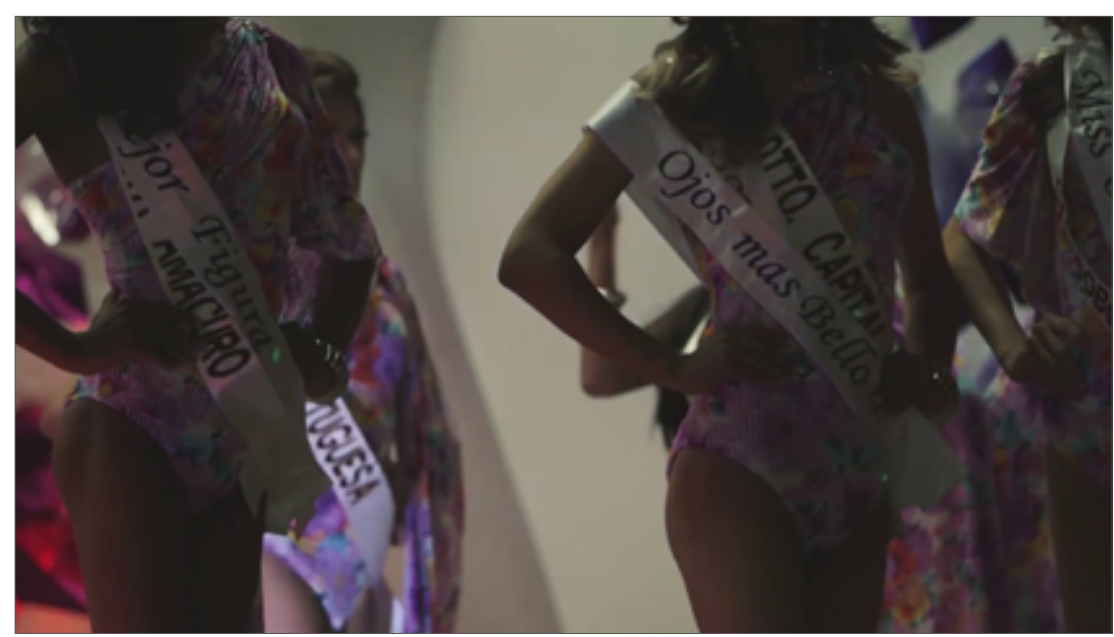

Imagen.1- El Arte de La Transformación (Isaac Uzcateguí y Pavlo Castillo, 2016).

Este corto se abre y se cierra con la referencia del público vivando a las dos finalistas con un grito colectivo que reclama la coronación (“¡Corona! ¡Corona!”), donde el demoledor ideal de belleza, impuesto a las mujeres en todo el universo, se esgrime como una utopía deseada. Esta idea es resaltada por una de Ixs protagonistas, Luna Indriago (Francisco Pérez, coronadx como "Miss Barinas") cuando expresa: "No es solamente un maquillaje, no es solamente

Disponible en:

https://www.youtube.com/watch?v=yih8DArp7jo

Consultado el 23 de diciembre de 2019. 
una peluca. Es un cuerpo, es un trabajo, es sacrificio, es dolor" (Uzcateguí y Castillo, 2016).

El film intenta dar cuenta de este tránsito a través de la contraposición de dos tipos de imágenes: austeras y brillantes. Las primeras pertenecientes a las entrevistas -a plena luz del día, en exteriores, desde primeros planos que adoptan el formato de lo que en el campo del cine documental se denomina como "cabezas parlantes" -; las segundas adjudicadas a las de la noche final del concurso, que a la vez podría ser leído como el "resultado" anhelado por sus participantes, artífices de sí mismxs mostrando su obra de arte acabada. "En una noche tan linda" es el título de la canción que corona la transformación final. El tránsito entre ambas figuraciones se encuentra condensado en una imagen porosa: Ixs participantes vestidxs de negro - sin montarse- pero con sus zapatos de taco alto puestos, ensayando la coreografía para el concurso que en algún punto Ixs iguala a todxs.

Quedan delimitadas así, las coordenadas espacio-temporales admitidas para la circulación de estos cuerpos. A la luz del día y en espacios exteriores, transitan aquellas identidades (autopercibidas) y cuerpos leídos como masculinos; mientras que, en el ámbito nocturno, sobre el escenario, bajo el encandilamiento de los reflectores, la pomposidad brillosa del vestuario y el maquillaje es donde emergen sus cuerpos y voces femeninas.

\section{UNA VOZ OTRA}

Unx de lxs transformistas de La otra se expresa diciendo: "es como de repente una voz adentro mío, o en mi cerebro, o en mi cabeza o donde fuese alrededor mío, dice 'al menos vos explícalo a través de la canción' y es una mujer la que me habla, en ese momento es una mujer la que me habla" (Martel, 1989). Se trata de un desdoblamiento, visible en la mayoría de las piezas del corpus, tanto en el discurso autobiográfico como en la práctica escénica que se elige mostrar donde uno de los recursos centrales es la fonomímica (lip-sync). En éste se inmiscuyen aquellos deseos y emociones expresados.

Si este desdoblamiento se manifiesta en una voz otra, podríamos hipotetizar que el recurso artístico opera como silenciamiento de la voz masculina para darle lugar a una voz femenina. De esta manera, se le dona el cuerpo propio a la voz femenina elegida. Como afirma el transformista Gustavo Laiza en el film "imitamos a la mujer, olvidándonos de que somos hombres" (Martel, 1989). Este transformismo como imitación se presenta más marcadamente en este corto de fines de la década del ochenta y cada vez se ve más desplazado de un mero lugar tradicional de "imitación de estrellas" hacia la construcción de una feminidad propia y elegida en los documentales más recientes del corpus. Así, por ejemplo, en el documental peruano de 2017, Nebulah (José Montoro, 2017) ${ }^{5}$-Lima, Perú (de formato más televisivo y hasta donde entendemos únicamente difundido vía web)- su únicx protagonista afirma "como Nebulah me siento otra persona, porque, si bien es cierto es un personaje, a la vez, yo lo he armado, yo lo he creado. Simplemente me permite expresarme (y hacer cosas con el público y con la gente que me sigue) que no hago como Joseph" (Montoro, 2017). Y agrega "El Drag queen yo lo veo como un arte. Yo siendo gay puedo ser Drag Queen, una persona heterosexual puede ser Drag Queen, una mujer puede ser Drag Queen” (2017).

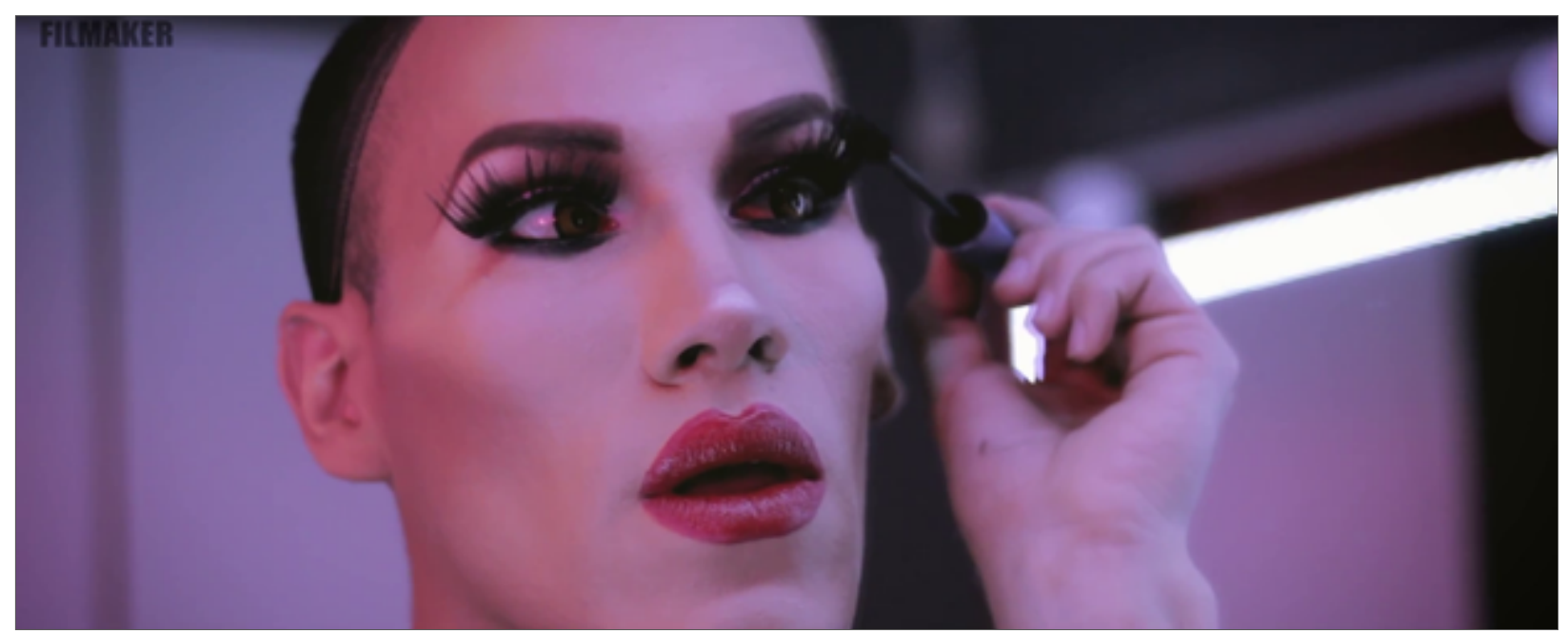

Imagen.2- Nebulah (José Montoro, 2017). 
Al igual que el documental venezolano de Uzcateguí y Castillo, donde aparece una multiplicidad de voces, el cortometraje La otra ${ }^{6}$ presenta una estructura que promueve el protagonismo de cuatro personajes. La película comienza, desde los títulos, y finaliza con la milonga "Se dice de mí" - con letra del poeta argentino Ivo Pelay, e históricamente recordada por la versión de Tita Merello en la película Mercado de abasto (1955, Lucas Demare)- interpretada por unx de Ixs protagonistas a través del procedimiento de la fonomímica. En la intimidad de la cocina de su casa, con el mate en la mano que emula un micrófono, la cámara nos devuelve su imagen a través del marco de una puerta donde Ix vemos pronunciar y bailar al ritmo de la canción. La entrevista primero tendrá lugar a través de una voz en off donde narra en primera persona lo que es el transformismo: "un hombre que de día es hombre y de noche sobre un escenario debe transformarse en una mujer" (Martel, 1989). De esta manera se produce una textura sonora que intercala y alterna la voz del performer, junto con la milonga porteña. muestra a otrx performer, quien también vive el transformismo de ese modo y cuenta sus inicios como bailarín de modern jazz.

La película entrelaza diferentes testimonios. Agrupa, por un lado, a personajes que viven el transformismo como trabajo y, por el otro, a personajes que asocian el transformismo a una identidad mutable, que se percibe en conflicto. Dentro de este último grupo, se observan dos casos: por ejemplo, Gustavo Laiza afirma: "Me hubiese gustado ser un hombre... completo. Y no un hombre a medias; porque tengo los sentimientos de un hombre, el pensamiento y la capacidad de un hombre. Pero me siento mujer muchas veces, no solamente en el escenario, no me da vergüenza decirlo, fuera de él, también, como muchos transformistas nos sentimos" (Martel, 1989); otrx entrevistadx expresa "cuando yo me estoy maquillando ya no sé si soy (...) pienso como un hombre, pienso como una mujer. Creo que (...) parte un poco de la locura que tenemos adentro de elegir esta profesión” (Martel, 1989).

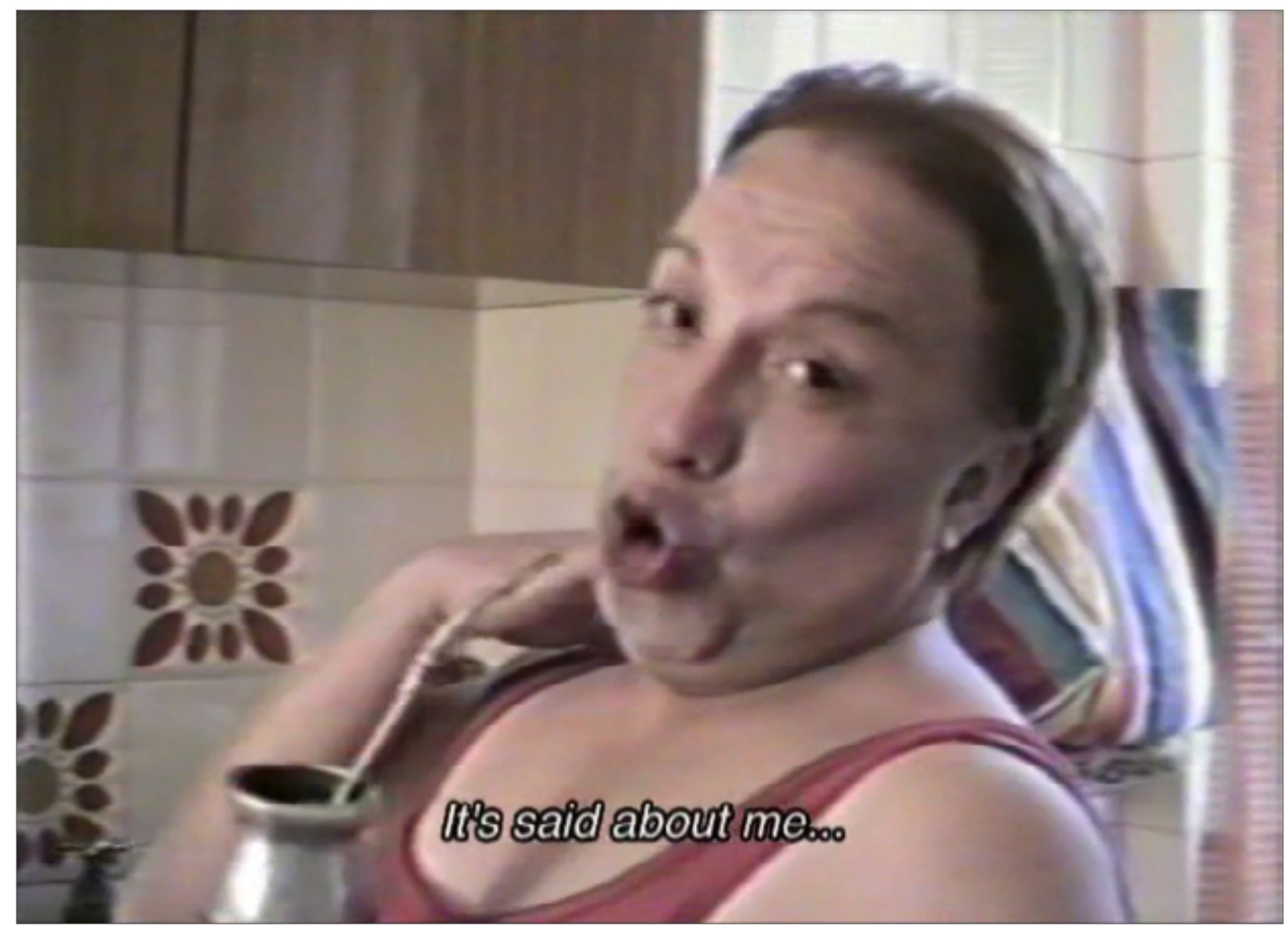

Imagen.3- La otra (Lucrecia Martel, 1989).

Posteriormente la narración se desplaza hacia otrx entrevistadx que se encuentra en el interior de su camarín fumando, quitándose sus joyas y maquillaje después de un espectáculo. La idea del transformismo como trabajo aparece en primer plano cuando afirma: "Este es el único país del mundo donde ser transformista es más fácil que ser barrendero" (Martel, 1989). A continuación, se tomará

6 Disponible en:

https://www.youtube.com/watch?v=AbuosfcMolM\&t=163s

Consultado el 10 de noviembre de 2019.
En el film de Martel, las canciones producen una "significación no natural” (Nasta, 2018), es decir se apoyan en la capacidad del espectador para percibir el porqué de la visión, o del uso de una canción (2018: 37). Así, de acuerdo con Dominique Nasta (2018), las canciones cumplen el rol de "potenciadores de sentido", ya que generan la voluntad de averiguar el impacto de la canción sobre la imagen. Para la autora, en este proceso opera una transformación de tipo metafórico donde, a partir de la fusión de dos ideas, nace una tercera (37). 
Por otra parte, Martel construye el relato a partir de una canción como "Se dice de mí", que remite al imaginario colectivo hispanohablante, donde quien mira el cortometraje difícilmente no está involucrado con el universo referencial de la cita. En Mercado del Abasto, Tita Merello interpreta a Paulina, la mujer varonil, masculinizada, pero que al mismo tiempo es "la flor del Abasto". Paulina es esa mujer con la que nadie se atreve a meterse, es la que despluma a los gallos, la que se encuentra en las sombras de los puestos del mercado y vigila todo lo que sucede a su alrededor con la visión de un águila. Es una muchacha que no está dotada de los "encantos femeninos" que la sociedad espera de toda mujer. De ella se dice "que camina a lo malevo", que en la jerga rioplatense, el término refiere a un hombre matón y pendenciero, provocador, asociado al mal vivir y diestro en el manejo del cuchillo. Su figura se convirtió en personaje de tangos y sainetes en las primeras décadas del siglo XX. Pero en este caso la expresión está aplicada a una figura femenina. Martel juega con los pliegues discursivos y sonoros de una canción que se encuentra en el imaginario espectatorial para describir a una mujer monstruosa, mitad hombre, mitad mujer. Pues lo monstruoso está asociado a todo aquello que no es identificable, a lo indiscernible. Aquello que alude a la mezcla, a la hibridez. Aquello que desencaja en las categorías fijas e inmutables de la modernidad. Aquello que excede al pensamiento binario.

Además, el título del film claramente alude a lo que unx de sus protagonistas en una secuencia define como esa voz "otra" que nace en su interior y que puja por salir. Es una voz de mujer. Al mismo tiempo, no podemos dejar de pensar cómo, a lo largo de la historia, desde la antigüedad clásica y pasando por la filosofía y la ciencia moderna, las mujeres han sido pensadas de manera misógina en términos de otredad, de segundo género, en tanto "continente desconocido", y siempre en relación con el género masculino desde un modelo de "una sola carne" (2019)7 que las construyó como hombre defectuoso. Estos elementos aparecen tematizados, no tanto desde una crítica sino de manera correctiva, en Mercado del Abasto, donde la mujer varonil es conquistada -aunque posteriormente engañada- por un galán y con la llegada de un hijo se convierte en madre ejemplar.

Durante La otra, en diferentes pasajes Ixs protagonistas aluden a "las capacidades de un hombre", y a que para ser mujer les hace falta lo más importante, es decir "haber nacido mujer”. Más allá de los dejos esencialistas/biologicistas de estas afirmaciones, el film pone en tensión lo femenino y lo masculino en un espectro de posibilidades que celebra la hibridez y las identidades mutables.

En este entramado contradictorio y mutable de discursos aparece algo que se evidencia, del mismo modo, en

Amparo Gómez Rodríguez (2019) analiza los escritos de Platón, $7 \quad$ Amparo Gómez Rodríguez (2019) analiza los escritos de Platón, humano en cuyo interior se piensa la diferencia sexual. Alli se constituye un modelo que la autora denomina como "de una sola carne" y de la "mujer-como-hombre". Las diferencias entre hombres y mujeres expresan una jerarquía sexual de grado que se advierten social y culturalmente y se consagran metafísicamente. Aristóteles formula un modelo de lo humano según un telos de perfección masculino, donde lo femenino se afirma como carencia, imperfección o falta. En el Renacimiento, con la filosofía y la ciencia moderna, se podría haber roto con el paradigma anterior. Sin embargo, este se vio reforzado. el plano musical: la queerización de los flujos musicales, entendida como el gesto de apropiación marica de ciertos géneros o cantantes o temas. ${ }^{8}$ Un puzzle artificial cuyo brillo se legitima mucho más que la biografía del seno familiar expulsivo y carente de acogida para estas identidades mutables. El gesto queer parece mostrarse en un entramado de identidades estratégicas que se arman como protección, como escudo, como empoderamiento, o como arte de sí mismx según el momento y el tiempo de la necesidad de sobrevida y búsqueda de realización personal.
8 Es llamativo que la canción "Se dice de mí" haya sido de inspiración para el proyecto de tango queer "Fifí tango", que interviene determinadas canciones y figuras desde una mirada marica. Véase: https://www.pagina12. com.ar/diario/suplementos/soy/1-4002-2015-05-22.html Consultado el 27 de diciembre de 2019. 


\section{SE DICE DE Mí}

El tópico de la mostración y el ocultamiento, la idea del transformismo como, en palabras de uno de los personajes del documental: "hacer una mujer sin dejar de ser un hombre" (Martel, 1989) se hacen visibles través de secuencias musicales como las del tema "If My Friends Could See Me Now", donde Ix protagonista a través del procedimiento de la fonomímica canta, baila y lentamente se quita el vestido, la peluca, y todos los ornamentos "femeninos" que Ix configuran como mujer. No es aleatoria la elección de esta referencia musical específica para realizar la performance, ya ahí aparece el gesto queer. Esta canción, con música de Cy Coleman y letra de Dorothy Fields, compone uno de los números inolvidables del musical Sweet Charity (1966), dirigido y coregrafiado por Bob Fosse. Charity es un personaje cargado de exotismo, al igual que el salón de baile donde trabaja, el "Fandango Ballroom". La película de este musical (dirigida por Bob Fosse en 1969) popularizó la interpretación de la misma realizada por Shirley MacLaine. Al mismo tiempo, debemos mencionar que este musical se inspira en otro film, Le notti di Cabiria (1957), de Fellini, donde la protagonista es víctima de numerosos desengaños amorosos. Las semejanzas (aunque también diferencias) entre Cabiria y Paulina son llamativas. Pero sobre todo, quisiéramos repensar el vínculo con el truco y el engaño, la mostración y ocultamiento que La otra tematiza, y donde las letras de estas canciones se convierten en motores que vehiculan y posibilitan la acción.

Resulta significativo que tres de los films escogidos contengan segmentos musicales que culminan en un striptease, donde lxs protagonistas, luego de sus números musicales en el escenario, se quitan las vestimentas, pelucas y rellenos que lxs configuran como cuerpos feminizados En línea con las ideas de Butler sobre las performance drag (2003), leemos estas secuencias a modo de striptease de género -en tanto estructura imitativa y de carácter contingente-. Sin embargo, como dijimos anteriormente, mientras que algunos personajes promueven un discurso que los acerca hacia la idea del transformismo en tanto trabajo; otros se encuentran vinculados a una identidad travesti, o en tensión permanente. Unx de Ixs performers de La otra afirma: "El travesti tiene todo adentro. No somos naturales somos todos fabricados" (Martel, 1989). Es en esta frase donde subyace el discurso transfóbico que intenta trazar una separación radical de las identidades travestis.

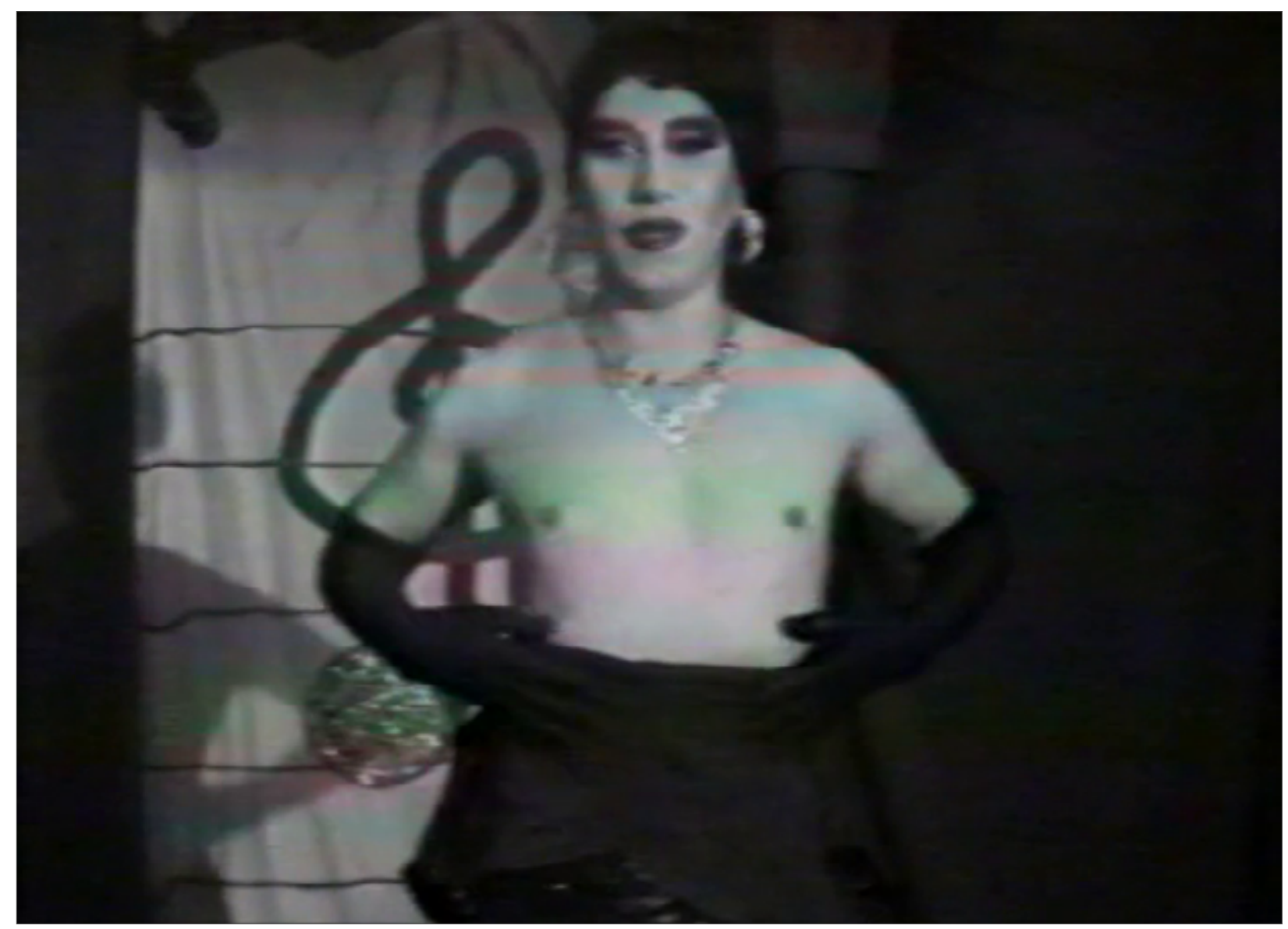

Imagen.4- La otra (Lucrecia Martel, 1989). 
Un striptease similar al de La otra se repite en Es mi vida (el arte de la transformación) ${ }^{9}$ y en Perra $^{10}$ con el segmento musical de la canción "Esta es mi vida”, de Raquel Olmedo. En este sentido, vale recordar el estudio de Judith Butler (2003: 323-326) al considerar las performances drag como exhibiciones hiperbólicas de la feminidad que promueven desplazamientos en las mismas reglas de género, las cuales resultan un ejemplo paradigmático como representación de las identidades paródicas que dan cuenta de la construcción social de género y de la repetición subversiva como estrategia política. Para Butler la performance drag, al imitar al género manifiesta la estructura imitativa de todo proceso de generización como también su carácter contingente.

El film La otra clausura con la frase de unx de lxs protagonistas asociadxs a una identidad travesti que afirma: "Para ser mujer nos faltaría lo más importante de la vida que es nacer mujer" (Martel, 1989). Si, a partir de las ideas de Butler (2003: 18-19), comprendemos al género como proceso de subjetivación (material y semiótico) y, simultáneamente, como ficción reguladora, la atribución de género es obligatoria, codifica y despliega nuestros cuerpos afectándonos materialmente. El "sexo" no solo funciona como norma, sino que además es parte de una práctica reguladora que produce los cuerpos que gobierna. El gesto estético y político de Martel de comenzar y culminar el film con una milonga como "Se dice de mí", ya desde la letra asociada a lo monstruoso, a principios de los noventa donde comienza a consolidarse un movimiento travesti en la Argentina y las prácticas transformistas se entrecruzan, consiste en dar voz a personajes silenciados, asociados a una escena marginal.

En un trabajo reciente, el cual toma en cuenta las críticas vertidas a la postura de Butler, Alba Pons Rabasa, estudiando los talleres Drag King, detalla cuatro procesos que, en la investigación feminista actual se han tornado "presupuestos inapelables en torno al género y la identidad" (2018: 77). A saber: "el desbordamiento constante e ineludible de las categorías identitarias, el cuestionamiento a la esencialidad y originalidad de la identidad, la toma de consciencia sobre la inexistencia de un a priori subjetivo y material, así como sobre la desnaturalización y el carácter interseccional de la identidad" (2018: 76-77). El recorrido temporal de nuestro corpus da cuenta de los avances y retrocesos de estas vivencias en las subjetividades de las personas que son retratadas en diferentes puntos de la geografía latinoamericana. Coincidimos con la investigadora cuando afirma: "El reto es crear herramientas que nos permitan aprehender, potenciar y analizar desde una perspectiva crítica encarnada, la multiplicidad de experiencias y prácticas implicada en los procesos de encarnación sexo-genérica que cuestionan la concepción de sujeto subyacente a las políticas sexuales contemporáneas. El drag puede ser una de ellas" (Pons Rabasa, 2018: 75). Aunque no necesariamente siempre lo sea, abre esa posibilidad, aún con sus tensiones con las luchas políticas identitarias.

9 Disponible en:

https://www.youtube.com/watch?v=-dTEE5YzhPs

Consultado el 8 de noviembre de 2019.

10 Disponible en:

https: / www.youtube.com/watch?time continue $=1 \& v=N$ eWjo $4 x e Q X$

Consultado el 8 de noviembre de 2019.

\section{ES MI VIDA, ESTA ES MI FORMA DE SER}

Es mi vida (el arte de la transformación) (Espinoza, 1995) compone una trama sonora que fusiona la música clásica con ritmos latinos, como la habanera y la rumba, para pasar por el pop, la música electrónica, y finalmente culminar con el tema "Esta es mi vida". En esta secuencia musical ininterrumpida se presentan imágenes que van desde el proceso de transformación en los camarines, hasta una abstracción y fusión de cuerpos. La música clásica, utilizada puntualmente al principio y al final de la secuencia, está relacionada, en el comienzo, con el tópico de la aceptación familiar narrado por unx de lxs intérpretes, y sobre el final, como el contraste o la contracara de las imágenes brillantes, del producto final mostrado en el escenario, pero que asimismo acarrea la dificultad de un modo de vida, en definitiva, de un modo de ser en una sociedad heterosexista, binaria y patriarcal. Por otra parte, las entrevistas en Perra (Navarro, Plaza y González, 2011) se inician respondiendo a la pregunta ¿cuándo te vestiste de mujer por primera vez? Este corto, producido en la Escuela Internacional de Cine y Tv, San Antonio de los Baños, Cuba, hace un particular foco en la recepción no sólo familiar sino social de la práctica drag y de las identidades autopercibidas como gay en la isla. En este sentido, llama particularmente la atención el inicio del film donde figuran imágenes de la vida cotidiana de la localidad de Güira (situada al norte de San Antonio de los Baños), los rostros anónimos de transeúntes, y la llegada del tren. Asimismo, se señala un intertexto cinematográfico que ayudó a la aceptación del colectivo gay en esa sociedad al valorar positivamente el éxito de la ficción Fresa y Chocolate (Gutierrez Alea y Tabío, 1993).

Al igual que en La Otra, y en Es mi vida (el arte de la transformación), la película promueve la multiplicidad de voces desde una estructura de cuatro protagonistas. Las entrevistas personales oscilan entre la arena pública y el espacio doméstico. Mientras que algunos personajes son retratados en el interior de sus casas realizando alguna actividad relacionada con su arte escénico, cercanos a una máquina de coser donde fabrican sus vestidos, o maquillándose; otros se encuentran transitando las calles del pueblo, o sentados cerca de una avenida que nos aproxima al movimiento de la localidad. A diferencia de otros films de nuestro corpus, las imágenes en el interior del camarín donde opera la transformación están prácticamente ausentes. Se suma a la vez, un hallazgo respecto de los otros documentales: el testimonio de una madre que finalmente terminó "aceptando" a su hijo.

Dos vectores rigen este film: las entrevistas personales, y el momento apoteótico donde Ix performer a través del procedimiento de la fonomímica interpreta la canción "Esta es mi vida", de Raquel Olmedo (actriz y cantante nacida en Caibarién -Las Villas, Cuba- pero residente en México, desde 1959). Mediante primeros planos e imágenes fuera de foco que se funden en el rostro de Ix protagonista, la cámara nos aproxima hacia la emotividad que culmina con el desborde del llanto.

Es llamativo que tres películas de nuestro corpus tomen esta canción para expresar la crudeza del tránsito vital de sus protagonistas y al mismo tiempo, cierto renacimiento. A su vez, su reiteración señala una pertenencia a una comunidad que se reconoce en esas referencias culturales. 
Se trata de una canción cuya letra expresa una autoafirmación identitaria enarbolada como bandera de lucha. La voz de Raquel Olmedo, afirma en este tema:

"Es mi vida, si bien o mal la he vivido/ esta es mi forma de ser, / de sentir, soy así. / Es mi vida, no me arrepiento de nada, / aún tengo mucho por vivir, por vivir, por vivir" ${ }_{11}$

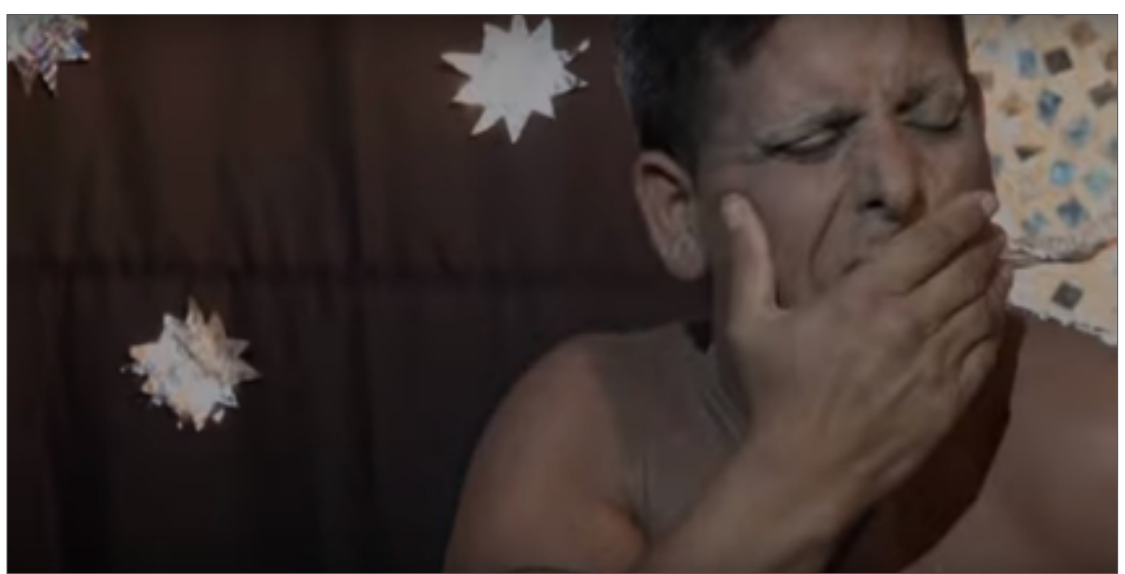

Imagen.5- Perra (Navarro, Plaza y González, 2011).

Canciones como esta, o como el tango "Se dice de mí", insertadas en los universos discursivos que despliegan los films, se convierten en vectores que dinamizan los afectos del público, ya que, de acuerdo con Richard Dyer (2011) al tener letra "pueden nombrar y promover emociones" (2011: 5) así como por su música "pueden desplegar una gama infinita de afectos" (5). Este autor subraya que las palabras de las canciones "pueden contar historias, describir paisajes, promover posturas políticas, hacer declaraciones filosóficas" (5). Así, en temas musicales como "Esta es mi vida", de Raquel Olmedo, al igual que en el tan recordado himno LGBTTIQ+, Soy lo que soy de Sandra Mihanovich, subyace la idea del orgullo, de aceptación social, de abandono de todo remordimiento y de afirmación una larga vida personal por vivir de manera libre.

Y continúa: “Tengo tanto amor que dar y te quiero regalar mi vida, 11 Y continúa: "Tengo tanto amor que dar y te quiero regalar mi vida, amor eso siempre he sido yo en la vida, / pero eso se acabó ahora sí sé quién soy yo en la vida".

\section{Conclusiones}

A lo largo de este trabajo hemos intentando trazar las coordenadas de un archivo que excede los límites impuestos por un canon y anida la pluralidad de voces y cuerpos subalternos. Mientras que, hacia finales del siglo XX, en documentales como La otra y Es mi vida (el arte de la transformación) sobrevuela la idea del transformismo como "imitación de estrellas", con la llegada del nuevo milenio advertimos un desplazamiento hacia la construcción de una feminidad propia y elegida en las piezas más recientes del corpus. En este sentido, observamos que películas como Perra y Nebulah enfatizan el tópico de la recepción familiar y social de la práctica drag y de las identidades autopercibidas como gays, a la vez que señalan un recorrido del activismo LGBTTIIQ+.

Es llamativo que el cortometraje Nebulah, a diferencia del resto de las producciones trabajadas en este corpus, esté subtitulado al inglés. Además de presentar una estética televisiva, Ix protagonista utiliza términos actuales como "seguidores" (provenientes de los usos de las plataformas del nuevo milenio: Youtube, Instagram, Twitter) y manifiesta la intención de llegar a nuevos públicos. No podemos dejar de mencionar tampoco, el impacto de fenómenos culturales actuales como por ejemplo, la serie estadounidense RuPaul's Drag Race (iniciada en el año 2009, y que hoy en día cuenta con once temporadas) en busca de la "Siguiente Superestrella Drag Estadounidense", transmitida por Netflix en Latinoamérica y España; o la reciente Pose, disponible en plataformas como $\mathrm{HBO}$, que realiza un recorrido por el activismo LGBTTIQ+ de la Nueva York de los años ochenta. En este sentido, recordamos al documental pionero de Jennie Livingston, Paris is Burning (1990), que relata el movimiento conocido como cultura ball en Nueva York, y los sectores sociales más implicados en él: gays latinxs y afro-americanxs, además de la comunidad trans, todos ellxs inmersxs en situaciones de exclusión social y pobreza. 
Cabe preguntarnos, entonces, cómo los diferentes medios determinan las elecciones estéticas de las producciones, y al mismo tiempo, cuáles son los fines políticos de las producciones en sí mismas. Así, podría decirse que una película como Paris is Burning y la serie Pose, refieren a un mismo escenario de época, pero sus formas difieren. Livingston, activista lésbica durante los años ochenta, realiza un documental con los colectivos implicados, desde un lugar de difusión, pero sobre todo de denuncia hacia las diferentes violencias que los atraviesan. Mientras que Pose, está producida para un público masivo (no siempre familiarizado con la temática), desde cierta espectacularización y sofisticación que vuelve atractivas las imágenes, pero que deja de lado la abyección de lxs implicadxs.

Dentro de las producciones escogidas en este artículo, se evidencian además, dos trabajos estudiantiles, el de Martel, y el de Navarro, Plaza y González. En el caso de La otra, que desde el extremo sur de América es contemporánea a la película de Livingston, subyace la intención de volver visible una práctica hasta el momento oculta. En 1995, en México, lo mismo sucede en el cortometraje de Espinoza. A diferencia de éstas, en una producción como Nebulah se establece un cambio en la autopercepción, con respecto a lxs protagonistas entrevistadxs en las otras películas: aquí su performer se piensa como drag. La internacionalización del término entra en concordancia, por un lado, con ciertos avances en materia de derechos, pero también con la asimilación capitalista de estas prácticas.

Tanto desde un transformismo, vinculado al trabajo o al hobby, o desde otro, asociado a una identidad travesti que posibilita en sus artífices otros modos de ser posibles, el recurso de la fonomímica (lip-sync) es una herramienta central para vehiculizar los deseos y sentires de lxs protagonistas de estos cortometrajes analizados. De esta manera, el plano musical se queeriza y configura un puzzle sonoro -nunca acabado- que reúne géneros y cantantes diversos, reunidos desde una selección marica camp que dibuja una comunidad cultural y afectiva cómplice en sus programas de lectura sexo-disidente del entramado artístico.

Si recordamos las palabras de unx de lxs performers de La otra que expresa la presencia de una voz femenina en su interior que reclama ser materializada, podríamos finalizar diciendo que estos personajes entregan, en cada performance, sus mundos a través de estas canciones. "Por siempre y para siempre tuyo es mi corazón feliz", entonada por Estela Raval en su versión hispanoamericana de “Hymne A L'Amour”, de Edith Piaf, es la frase con la que Martel decide clausurar su película.

Durante un recorte temporal de treinta años se hace visible que la presencia de estas voces en el cine de Latinoamérica es escasa, tan lateral e invisibilizada como las vidas sexodisidentes en sus sociedades de emergencia. La performance artística deviene identidad que habilita usos estratégicos de la voz y flujos por músicas diversas a las cuales lxs performers le prestan cuerpo y les entregan sus vidas sexodisidentes. 
Berkins, LohanA. (Comp.) (2007). Cumbia, copeteo y lágrimas. Buenos Aires: A.L.I.T.T.

BUTLER, JUDITH. (2003). Cuerpos que importan: sobre los límites materiales y discursivos del sexo. Buenos Aires: Paidós.

Campuzano, Giuseppe. (2007). Museo travesti del Perú. Perú: Giuseppe Campuzano editor.

FIgARI, CARLos. (2009). Eróticas de la disidencia en América Latina. Brasil, siglos XVII al XX. Buenos Aires: CLACSO-Ciccus.

Gómez Rodríguez, Amparo. (2019). “El modelo de una sola carne en las ciencias biomédicas de la antigüedad clásica”, en Escritos sobre ciencia y género, Madrid: Los libros de la Catarata.

HALBERSTAM, JACK. (2018). Trans* A Quick and Quirky Account of Gender Variability. Oakland, California: University of California Press.

Lozano, Ezequiel. (2015). Sexualidades disidentes en el teatro. Buenos Aires, años 60. Buenos aires: Biblos.

Nasta, Dominique. (2018). "Canción y significación en el cine. Medio siglo de caminos cruzados (1964-2014)" en Conozco la canción. Melodías populares en los cines posclásicos de América Latina y Europa, Piedras, Pablo y Dufays, Sophie (eds.), Buenos Aires: Libraria.

Peralta, Jorge luis y Mérida Jiménez, Rafael M. (eds.) (2015). Memorias, identidades y experiencias trans: (In)visibilidades entre Argentina y España. Buenos Aires: Editorial Biblos.

Pons Rabasa, Alba. (2018). "Los talleres Drag King: Una metodología feminista de investigación encarnada”. Investigación teatral, 9 (13). México: Universidad Veracruzana, 57-79.

Wayar, Marlene. (2018). Travesti / Una teoría lo suficientemente buena. Buenos Aires: Muchas Nueces. 